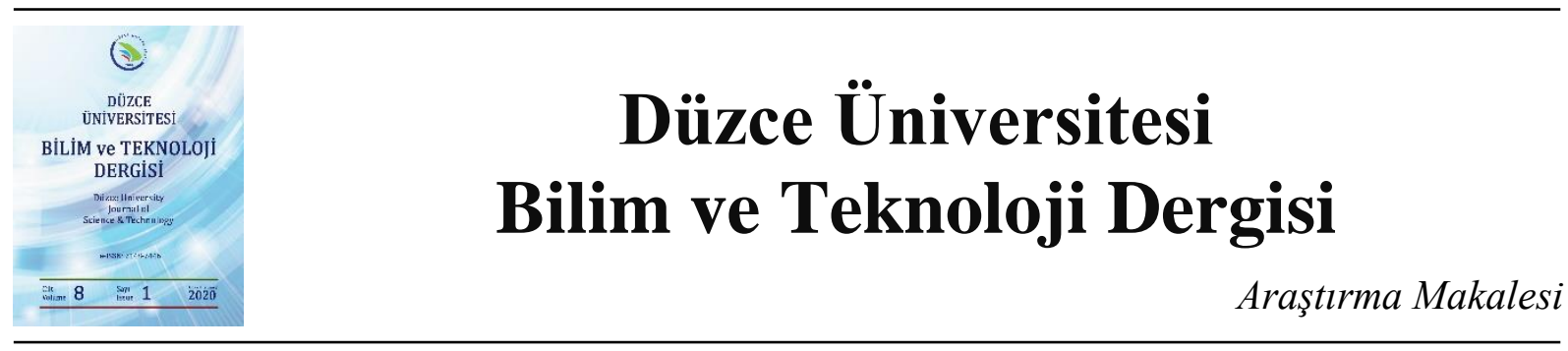

\section{Kutu Enkesitli Sandviç Tipi Çelik Çaprazların Çevrimsel Yük Etkisindeki Davranışlarının Deneysel Olarak İncelenmesi}

\author{
Ayşegül DURMUŞ DEMIR ${ }^{\text {a,* }}$ \\ a, İnşaat Mühendisliği Bölümü, Mühendislik Fakültesi, Karadeniz Teknik Üniversitesi, Trabzon, TÜRKIYYE \\ * Sorumlu yazartn e-posta adresi: aysegul@ktu.edu.tr \\ DOI : 10.29130/dubited.565195
}

\begin{abstract}
ÖZET
$\mathrm{Bu}$ çalışmada, yapısal sistemlerde yanal yük taşıyıcı elemanlar olarak kullanılan, kutu enkesitli geleneksel çelik çapraz elemanların burkulma davranışının kontrolü için bir yöntem önerilmektedir. Önerilen yöntemde, kutu enkesitli çelik çapraz içten ve dıştan iki ayrı kutu profilin arasına yerleştirilerek sandviç tipi bir çelik çapraz eleman elde edilmiştir. Burkulma kontrolünü sağlamak için kullanılan iç ve dış profillerin boyu yanal yük taşıyıcı elemanın boyundan daha kısa bırakılarak, bu profillerin eksenel yük taşımaları engellenmiştir. Deneysel çalışmalar kapsamında bir adet kutu enkesitli sandviç tipi çelik çapraz ile aynı özelliklerdeki kutu enkesitli profilden üretilmiş bir geleneksel çelik çapraz çevrimsel yük etkisinde test edilmiş̧ir. Elde edilen bulgular yük taşıma kapasitesi, burkulma yerdeğiştirmesi ve enerji tüketme kapasitesi açısından karşılaş̧ırılımalı olarak incelenmiştir. Sonuç olarak, önerilen burkulma kontrolü tasarımının, geleneksel çelik çaprazların yük taşıma kapasitesini, burkulma yerdeğiştirmesini ve enerji tüketme kapasitesini artırdığı belirlenmiştir.
\end{abstract}

Anahtar Kelimeler: Burkulma kontrolü, Çelik çapraz, Çevrimsel yük

\section{Experimental Investigation of Box Cross-Sectional Sandwich Type Steel Braces under Cyclic Loading}

\begin{abstract}
Box cross-sectional traditional steel braces are used in structural systems as lateral load-bearing elements. In this study, a method for controlling the buckling behavior of these braces is proposed. In the proposed method, this type of steel brace was placed between the inside and outside of the two separate box profiles to obtain a sandwich type steel brace element. The length of the inner and outer tubes used to ensure buckling control is kept shorter than the length of the lateral load-bearing element. Thus, no axial forces are to be transmitted to these tubes. In the scope of experimental studies, a box cross-sectional sandwich type steel brace and a conventional steel brace, produced from the same box cross sectional tube with the same properties, were tested under cyclic loading. The findings were examined in terms of load bearing capacity, buckling displacement and energy consumption capacity. Experimental results reveal that the proposed buckling control design increased all examined parameters of box cross-sectional traditional steel braces.
\end{abstract}

Keywords: Buckling control, Steel brace, Cyclic loading 


\section{GiRis}

Yapılarda en yaygın olarak kullanılan yanal yük taşıyıcı sitemlerden birisi, yüksek rijitlikleri, ucuz ve kolay uygulanabilir olmaları nedeniyle, çelik çapraz elemanlardır. Yapısal sistemlerde çelik çaprazlardan beklenen davranış, yeterli rijitlik, süneklik ve enerji tüketimini sağlamalarıdır [1]. Bu elemanların çekme ve basınç yüklemesi altında akma ve burkulma davranışları göstererek enerji tüketimi sağladığı kabul edilmektedir. Ancak çapraz elemanların enerji tüketme kapasiteleri burkulma problemi nedeniyle oldukça sınırlı kalabilmektedir. Çevrimsel yük uygulanan çapraz elemanlar basınç etkisi altında, çekmede olduğu gibi, büyük boyuna şekildeğiştirmeler yapamayarak burkulmaktadırlar. Çevrimsel yüklemede ilerleyen çevrimlerde çekme kuvveti etkisiyle artan şekildeğiştirmeler, çaprazın orta bölgelerinde burkulma nedeniyle meydana gelen hasarın her çevrimde giderek artmasına neden olmakta ve burkulma yükü her çevrimde biraz daha azalmaktadır [2]. Öte yandan, depreme maruz çok katlı yapılarda, çaprazların burkulma nedeniyle göçmesi hasarın bazı katlarda yoğunlaşmasına ve yumuşak kat oluşmasina sebep olabilmektedir [3].

Çelik çaprazlardaki burkulma problemini gidererek, bunların çevrimsel başarımını artırmak için bugüne kadar başta burkulması önlenmiş çelik çaprazlar olmak üzere birçok çalışma yapılmıştır [4-8]. Bunlardan beton dolgulu burkulması önlenmiş çelik çaprazlar, geleneksel çelik çaprazların aksine, basınç etkisinde de tıpkı çekme etkisinde olduğu gibi büyük boyuna şekildeğiştirmeler yaparak enerji tüketmekte ve burkulma meydana gelmeden kararlı bir çevrimsel davranış sergilemektedirler $[4,5]$. Son yıllarda ise, beton dolgulu burkulması önlenmiş çelik çaprazlar yerine tamamı çelik burkulması önlenmiş çelik çapraz sistemler geliştirilmiştir [6-8]. Bu sistemlerde burkulma kontrolü, çelik çekirdeğin plakalarla [6,7] ya da çelik kutu veya boru profiller [8] ile dıştan sarılması ile sağlanmakta olup, bunlarda da beton dolgulu burkulması önlenmiş çelik çaprazlar ile aynı çalışma prensibi geçerlidir. Çelik plakalarla sağlanan burkulma kontrolünde çeşitli ebatlarda levha ve profillerin yanı sıra çok sayıda civata ve kaynak kullanıldığı için boru veya profillerle yapılan burkulma kontrolüne göre daha karmaşı ve maliyetlidir.

$\mathrm{Bu}$ çalışmada ise kutu enkesitli geleneksel çelik çaprazlar için sandviç tipi bir burkulma kontrollü çelik çapraz tasarımı önerilmektedir. Önerilen tasarımda, yanal yük taşıyıcı çelik kutu profil içten ve dıştan iki ayrı kutu profilin arasına yerleştirilerek sandviç tipi bir çelik çapraz eleman elde edilmiştir. Çalışma kapsamında, önerilen sistemle karşılaştırılmak amacıyla kutu enkesitli geleneksel bir çelik çapraz üretilerek elde edilen iki deney elemanı çevrimsel yük etkisinde test edilmiştir. Elde edilen bulgular, deney elemanlarının çevrimsel davranışları incelenerek yük taşıma kapasitesi, burkulma yerdeğiştirmesi ve enerji tüketme kapasiteleri açısından karşılaştırılmıştır.

\section{Deneysel Calismalar}

\section{A. DENEY ELEMANLARI VE DENEY DÜZENEĞİ}

Deneysel çalışma kapsamında iki adet deney elemanı üretilmiştir. Bunlardan kutu enkesitli geleneksel çelik çaprazları temsil etmek amacıyla üretilen deney elemanı GÇ, sözkonusu elemanların burkulma problemini iyileştirmek amacıyla tasarlanan sandviç tipi deney elemanı ise ST olarak isimlendirilmiştir. Deney elemanlarının üretiminde S355JR kalitesindeki çelik profiller kullanılmıştır. GÇ ve ST deney elemanları $70 * 70 * 3 \mathrm{~mm}$ enkesitli kutu profilden üretilmiştir. Bununla birlikte ST elemanında burkulma önleyici olarak ise çelik çaprazın içinde $60 * 60 * 3 \mathrm{~mm}$ ebatlarında, dışında ise $80 * 80 * 3 \mathrm{~mm}$ ebatlarında kutu enkesitli profiller kullanılmıştır. Her iki elemanın da mafsaldan mafsala uzunluğu (L) $2000 \mathrm{~mm}$ ve net uzunluğu $\left(\mathrm{L}_{\mathrm{n}}\right) 1740 \mathrm{~mm}$ ' dir. ST elemanında kullanılan iç ve dış burkulma önleyicilerin uzunlukları ise $l=1680 \mathrm{~mm}$ olarak belirlenmiştir (Tablo 1). Burkulma önleyicilerin uzunluğu çelik çaprazın net uzunluğundan kısa tutularak, bunların eksenel basınç ve çekme yükü almaları engellenmiştir (Şekil 1). İç ve dış profiller çelik çaprazdan bağımsız olarak 
çapraz doğrultusunda hareket kabiliyetine sahiptir. Önerilen ST deney elemanının bileşenleri ve kendisi Şekil 2'de gösterilmektedir.

Tablo 1. Deney elemanlarının boyutları $(\mathrm{mm})$

\begin{tabular}{|c|c|c|c|c|c|c|c|c|c|c|}
\hline \multirow{3}{*}{$\begin{array}{c}\text { Deney } \\
\text { Elemanı }\end{array}$} & \multicolumn{4}{|c|}{ Çelik Çapraz } & \multicolumn{6}{|c|}{ Burkulma önleyici } \\
\hline & \multirow[b]{2}{*}{ 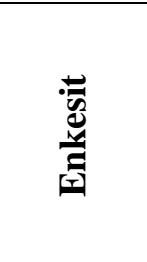 } & \multirow[b]{2}{*}{ مَّ } & \multirow[b]{2}{*}{ 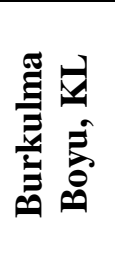 } & \multirow[b]{2}{*}{ 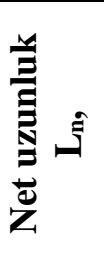 } & \multicolumn{3}{|c|}{ İç } & \multicolumn{3}{|c|}{ Dış } \\
\hline & & & & & 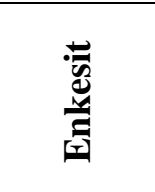 & 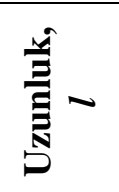 & 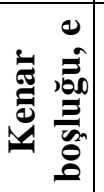 & 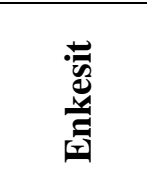 & $\frac{\stackrel{n}{E}}{\mathbb{E}}$ & 离 \\
\hline $\mathrm{GÇ}$ & $70 * 70 * 3$ & 2000 & 2000 & 1740 & - & - & - & - & - & - \\
\hline ST & $70 * 70 * 3$ & 2000 & 2000 & 1740 & $60 * 60 * 3$ & 1680 & 30 & $80 * 80 * 3$ & 1680 & 30 \\
\hline
\end{tabular}
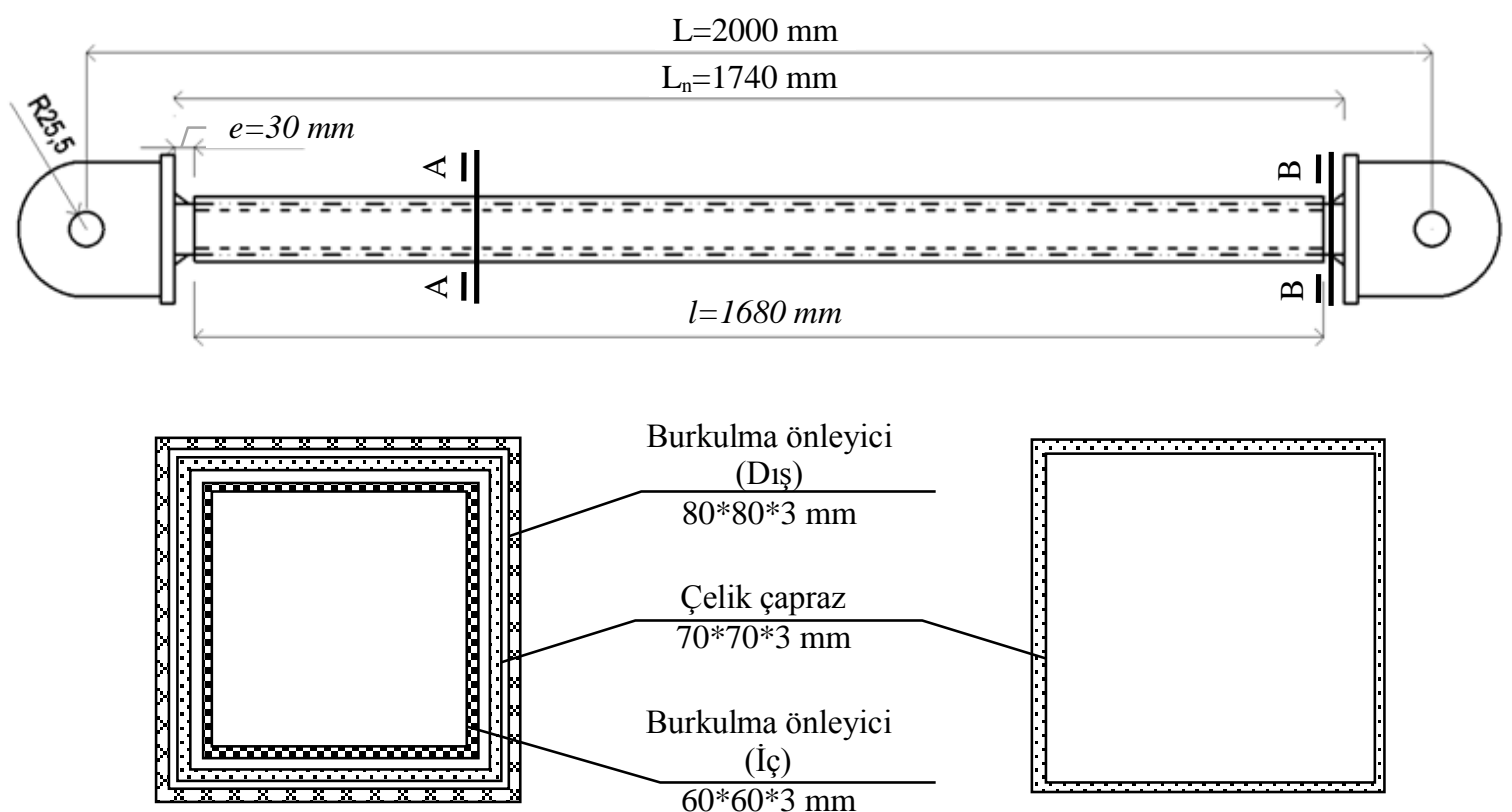

A-A kesiti

B-B kesiti

Şekil 1. ST elemanının şematik görünümü

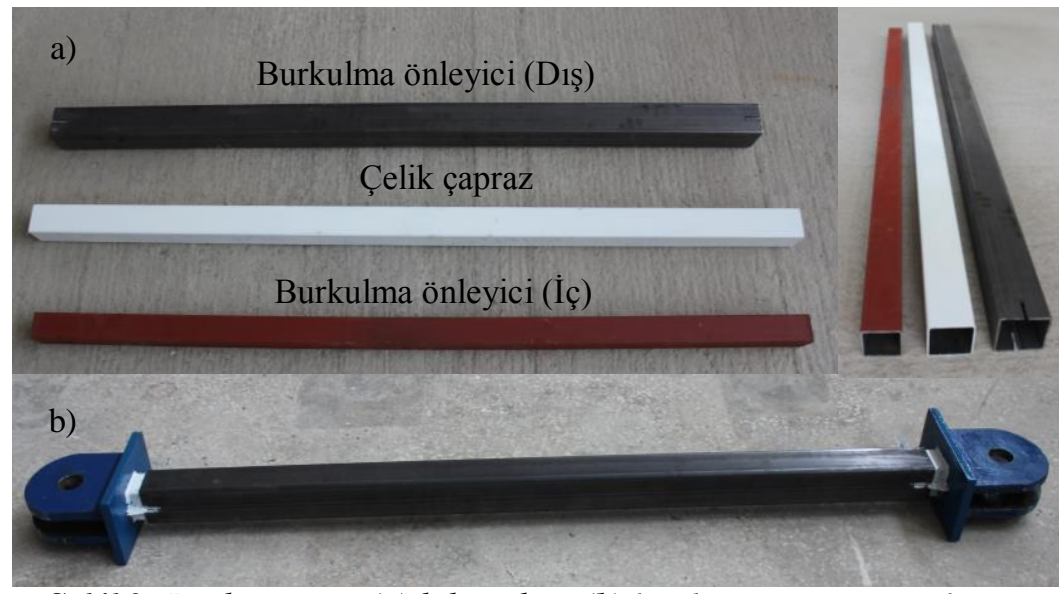

Şekil 2. ST elemanının (a) bileşenleri, (b) kendisine ait görünümler 
Deney düzeneği Şekil 3' te gösterilen mafsallı birleşime sahip bir rijit yükleme kolonu ve kirişinden meydana gelmektedir. Deneylerde yatay yük ve yatay yerdeğiştirme ölçümleri yapılmıştır. Çevrimsel yüklemeler yerdeğiştirme kontrollü bir hidrolik piston ile gerçekleştirilmiş olup deneylerde kullanılan yükleme protokolü Tablo 2'de verilmiştir. Deneyler sırasında hidrolik pistonun ucuna yerleştirilen 500 kN kapasiteli bir yük hücresi ile yük ölçümleri yapılmıştır. Yükleme kolonunun yatay yerdeğiştirmesi ise potansiyometrik cetvel (LPDT) yardımıyla ölçülmüştür. Ölçümler Coda AI8b veri toplama cihazı ile kayıt altına alınmıştır.

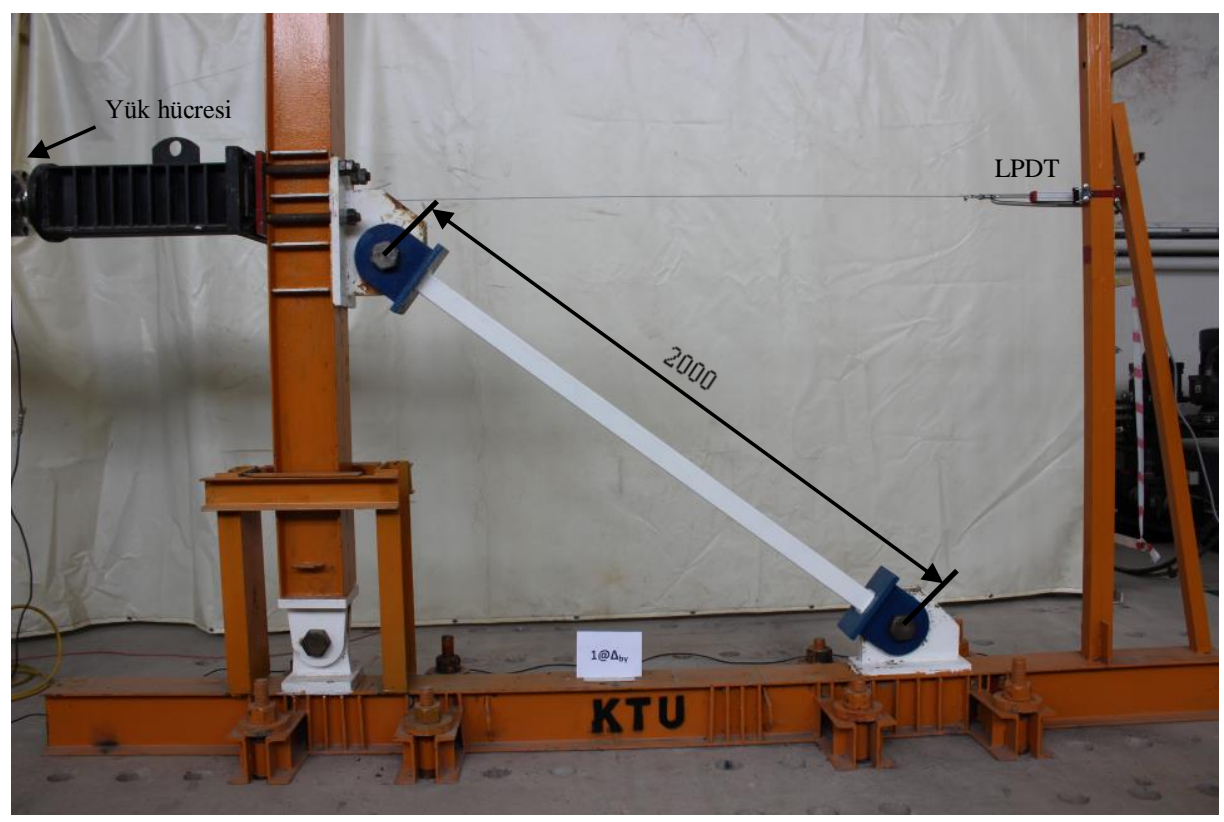

Şekil 3. Deney düzeneği

Tablo 2. Deneylerde kullanilan yükleme protokolü

\begin{tabular}{c|ccccc}
\hline Yerdeğiştirme adımı & 1 & 2 & 3 & 4 & 5 \\
\hline Çevrim sayısı ve Genliği & $2 @ 2 \mathrm{~mm}$ & $2 @ 5 \mathrm{~mm}$ & $2 @ 13,95 \mathrm{~mm}$ & 2@27,90 mm & 2@42,50 mm \\
\hline
\end{tabular}

\section{BULGULAR VE İRDELEMELER}

Deneylerden elde edilen çevrimsel yük-yerdeğiştirme eğrileri Şekil 4'de gösterilmektedir. Deney elemanlarının itme ve çekmede elde edilen başlangıç rijitlikleri $\left(\mathrm{K}_{\mathrm{y}}\right)$, akma yükleri $\left(\mathrm{P}_{\mathrm{y}}\right)$ ve maksimum yükleri ( $\left.\mathrm{P}_{\text {maks }}\right)$ ile bunlara karşl1ık gelen yerdeğiştirme değerleri $\left(\delta_{\mathrm{y}}\right.$ ve $\left.\delta_{\text {maks }}\right)$ ise Tablo 3 'de verilmektedir. 

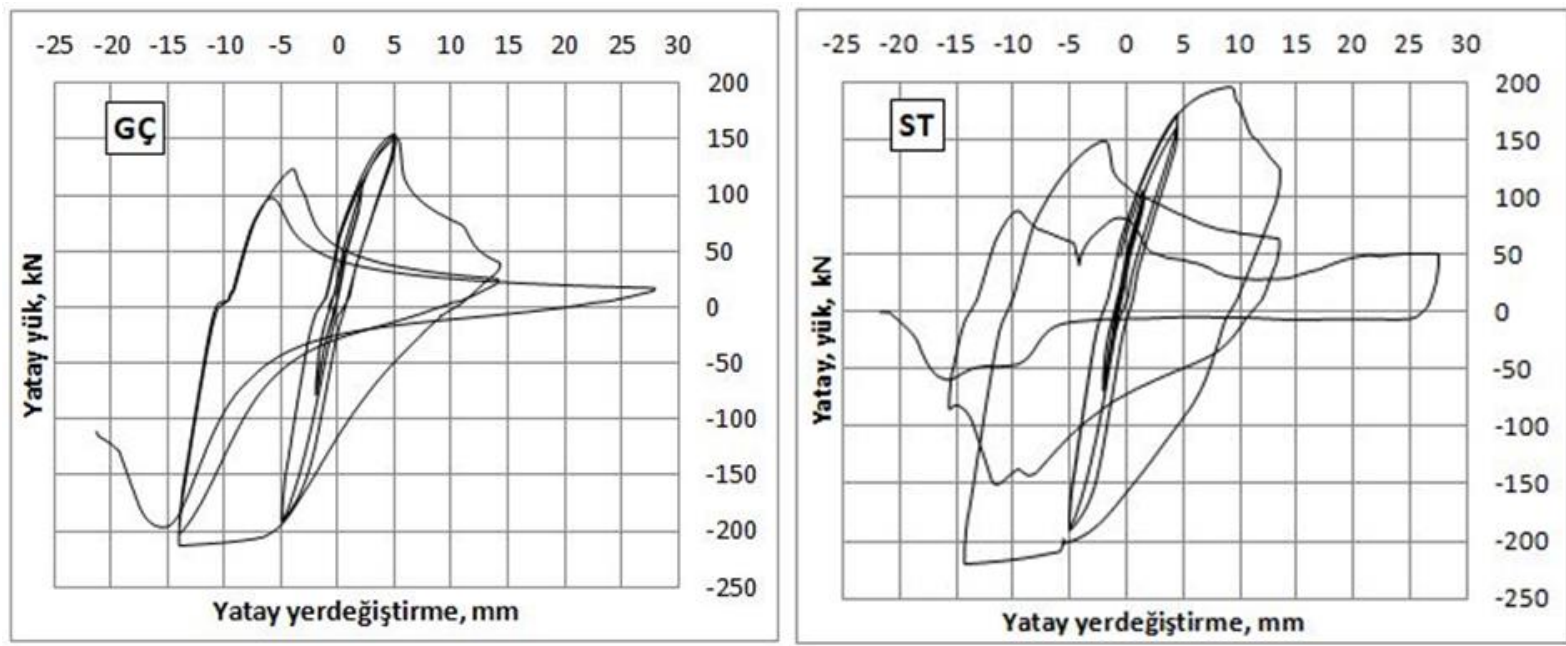

Şekil 4. Deney elemanlarının çevrimsel yük etkisindeki başarımları a) GÇ elemanı, b) ST elemanı

Tablo 3. Deney sonuçlart

\begin{tabular}{|c|c|c|c|c|c|c|}
\hline \multirow{3}{*}{$\begin{array}{l}\text { Deney } \\
\text { elemanı }\end{array}$} & \multicolumn{6}{|c|}{ Akma yükü } \\
\hline & \multicolumn{3}{|c|}{ İtme (+) } & \multicolumn{3}{|c|}{ Çekme (-) } \\
\hline & $\begin{array}{c}\mathbf{P}_{\mathbf{y}} \\
(k N)\end{array}$ & $\begin{array}{c}\boldsymbol{\delta}_{\mathbf{y}} \\
(\mathrm{mm})\end{array}$ & $\begin{array}{c}\mathbf{K}_{\mathbf{y}}{ }^{*} \\
(\mathrm{kN} / \mathrm{mm})\end{array}$ & $\begin{array}{c}\mathbf{P}_{\mathbf{y}} \\
(k N)\end{array}$ & $\begin{array}{c}\boldsymbol{\delta}_{\mathbf{y}} \\
(\mathrm{mm})\end{array}$ & $\begin{array}{c}\mathbf{K}_{\mathbf{y}}{ }^{*} \\
(\mathrm{kN} / \mathrm{mm})\end{array}$ \\
\hline GÇ & 153.46 & 4.89 & 31.38 & -190.62 & -4.96 & 38.43 \\
\hline ST & 172.88 & 4.54 & 38.08 & -190.70 & -4.95 & 38.52 \\
\hline \multirow{3}{*}{$\begin{array}{l}\text { Deney } \\
\text { elemanı }\end{array}$} & \multicolumn{6}{|c|}{ Maksimum yük } \\
\hline & \multicolumn{3}{|c|}{ İtme (+) } & \multicolumn{3}{|c|}{ Çekme (-) } \\
\hline & $\begin{array}{l}\mathbf{P}_{\max } \\
(k N)\end{array}$ & & $\begin{array}{c}\boldsymbol{\delta}_{\max } \\
(\mathrm{mm}) \\
\end{array}$ & $\begin{array}{l}\mathbf{P}_{\max } \\
(k N)\end{array}$ & & $\begin{array}{c}\boldsymbol{\delta}_{\max } \\
(\mathrm{mm})\end{array}$ \\
\hline GÇ & 153.46 & & 4.89 & -213.13 & & -14.01 \\
\hline ST & 196.13 & & 9.22 & -219.86 & & -14.17 \\
\hline
\end{tabular}

${ }^{*}$ :Başlangıç rijitliği: $K_{y}=P_{y} / \delta_{y}$

Kutu enkesitli geleneksel çelik çaprazları temsil eden GÇ isimli deney elemanı ikinci yerdeğiştirme adımının ilk çevriminde akma yüküne ulaşmıştır. Akma anında yerdeğiştirme $4.89 \mathrm{~mm}$, yük ise 153.46 $\mathrm{kN}$ olarak ölçülmüş ve başlangıç rijitliği $31.38 \mathrm{kN} / \mathrm{mm}$ olarak elde edilmiştir. Üçüncü yerdeğiştirme adımının ilk çevriminde ise sistemde burkulma meydana gelmiştir. Burkulma anında yerdeğiştirme $5.121 \mathrm{~mm}$, yük ise $149.95 \mathrm{kN}$ olarak ölçülmüş̧ür (Şekil 5a). Aynı çevrimde yaklaşık 10.99 mm' lik yerdeğiştirmede çaprazın orta bölgesinde yerel burkulma meydana gelmiştir (Şekil 5b). İlerleyen çevrimlerde hasar yerel burkulma bölgesinde yoğunlaşmıştır. \% 2 göreli kat ötelenme oranında GÇ elemanının yük taşıma kapasitesi itmede $16.02 \mathrm{kN}$ ' a düşerken, çekmede $-21.28 \mathrm{~mm}$ 'lik yerdeğiştirmede numune göçmüştür (Şekil 6). 


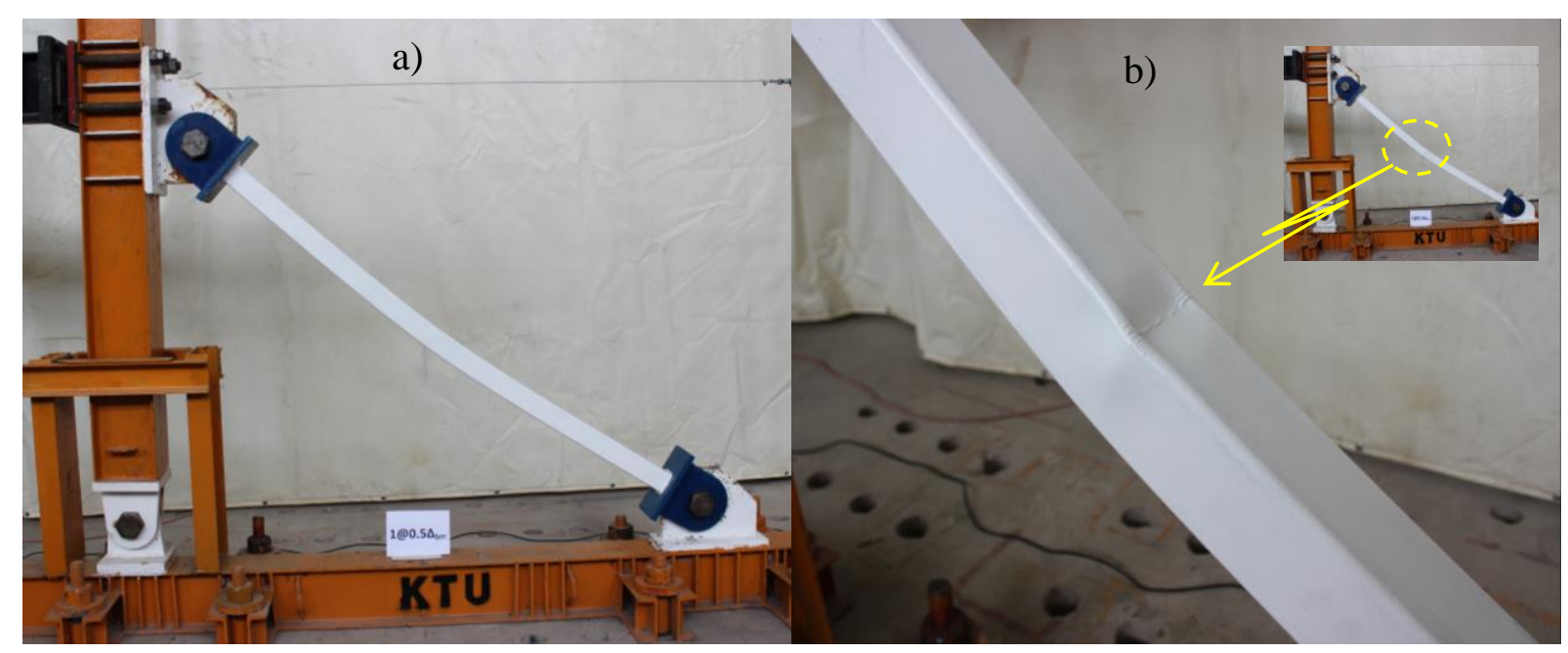

Şekil 5. GÇ elemanındaki hasarlar: a) genel burkulma, b) yerel burkulma

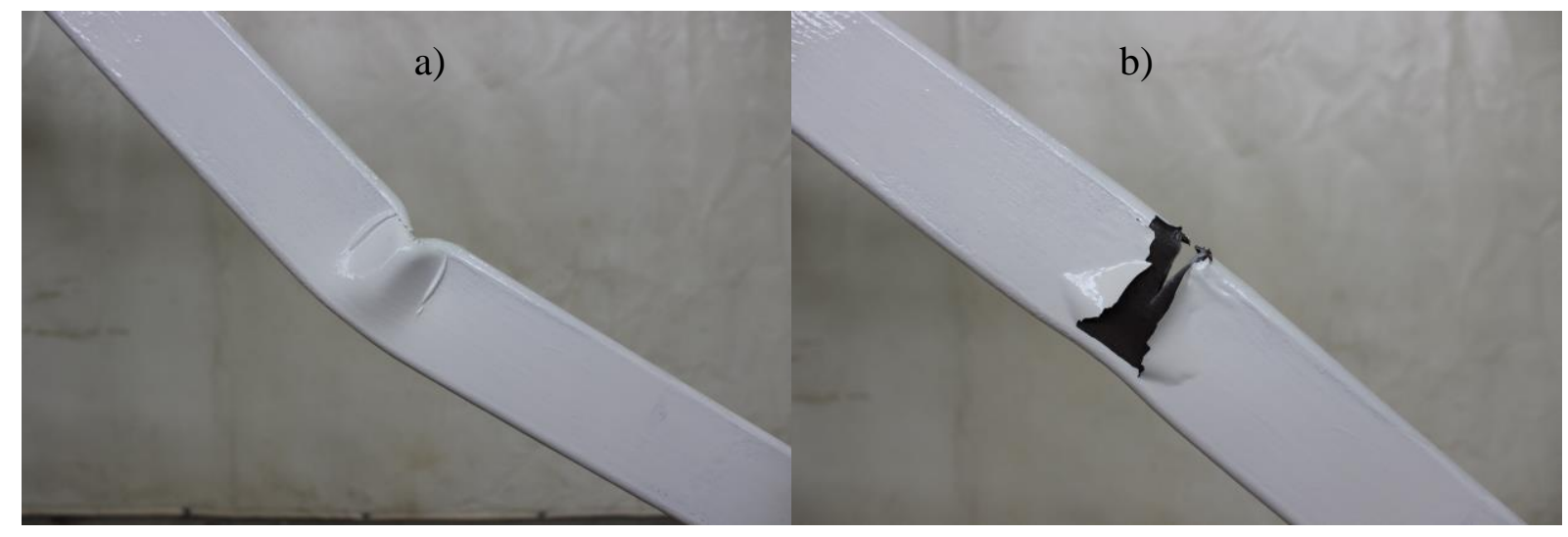

Şekil 6. GÇ elemanının göçme anı: a) itme, b) çekme

Kutu enkesitli geleneksel çelik çaprazlarda burkulma kontrolü sağlamak için tasarlanan ST isimli sandviç tipi deney elemanı ise ikinci yerdeğiştirme adımının ilk çevriminde akma yüküne ulaşmıştır. Akma anında yerdeğiştirme $4.54 \mathrm{~mm}$, yük ise $172.88 \mathrm{kN}$ olarak ölçülmüş ve başlangıç rijitliği 38.08 $\mathrm{kN} / \mathrm{mm}$ olarak elde edilmiştir. Üçüncü yerdeğiştirme adımının ilk çevriminde, $9.22 \mathrm{~mm}$ 'lik yerdeğiştirme seviyesine kadar burkulma meydana gelmemiş ve yük taşıma kapasitesi 196.13 kN'a ulaşmıştır. Ancak bu aşamadan hemen sonra, deney elemanının her iki ucunda bulunan, iç ve dış burkulma kontrolü yapılmayan $30 \mathrm{~mm}$ uzunluğundaki kenar boşluğu bölgelerinden birinde yerel burkulma meydana gelmiştir (Şekil 7). İlerleyen çevrimlerde bu bölgede ağır hasarlar meydana gelmeye başlamış ve bu durum yük-yerdeğiştirme eğrisinde de ani düşüşlere neden olmuştur (bkz. Şekil 4). ST elemanının yük taşıma kapasitesi \%2 göreli kat ötelenme oranında itme de 50.68 kN'a düşerken çekmede -21.27 mm yerdeğiştirme seviyesinde göçme meydana gelmiştir (Şekil 8). 


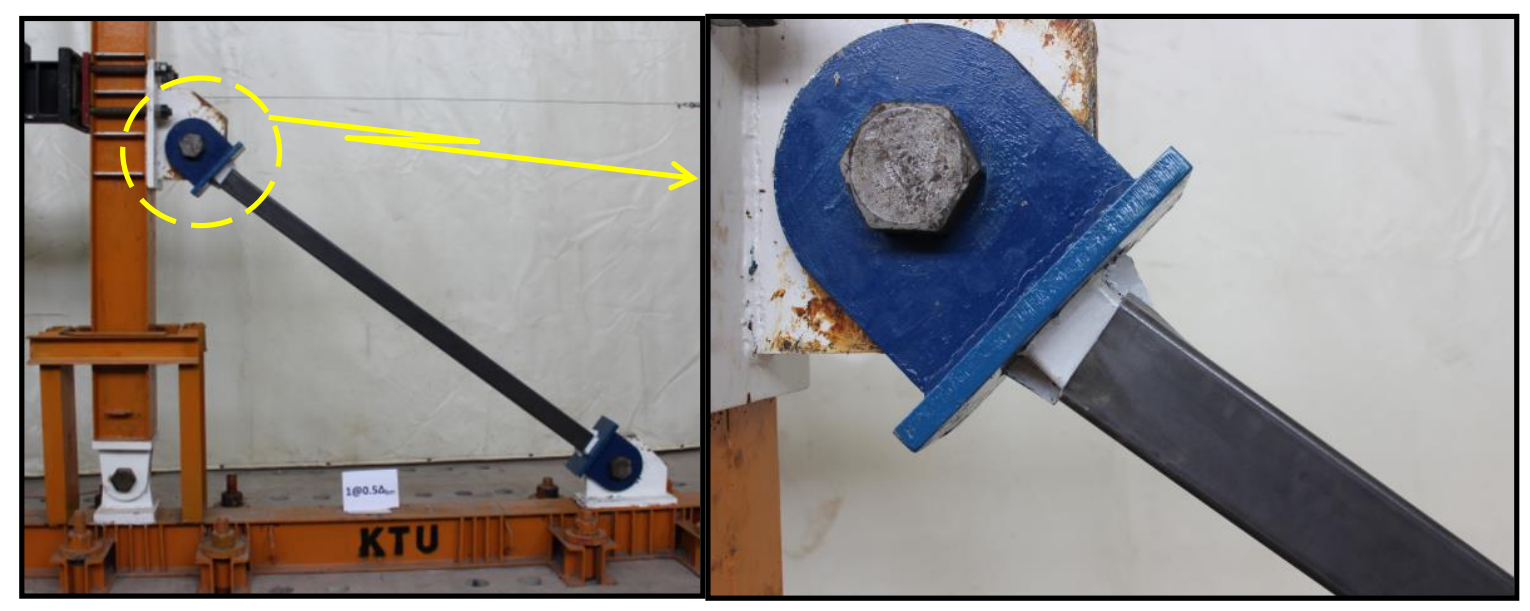

Şekil 7. ST elemaninda yerel burkulma

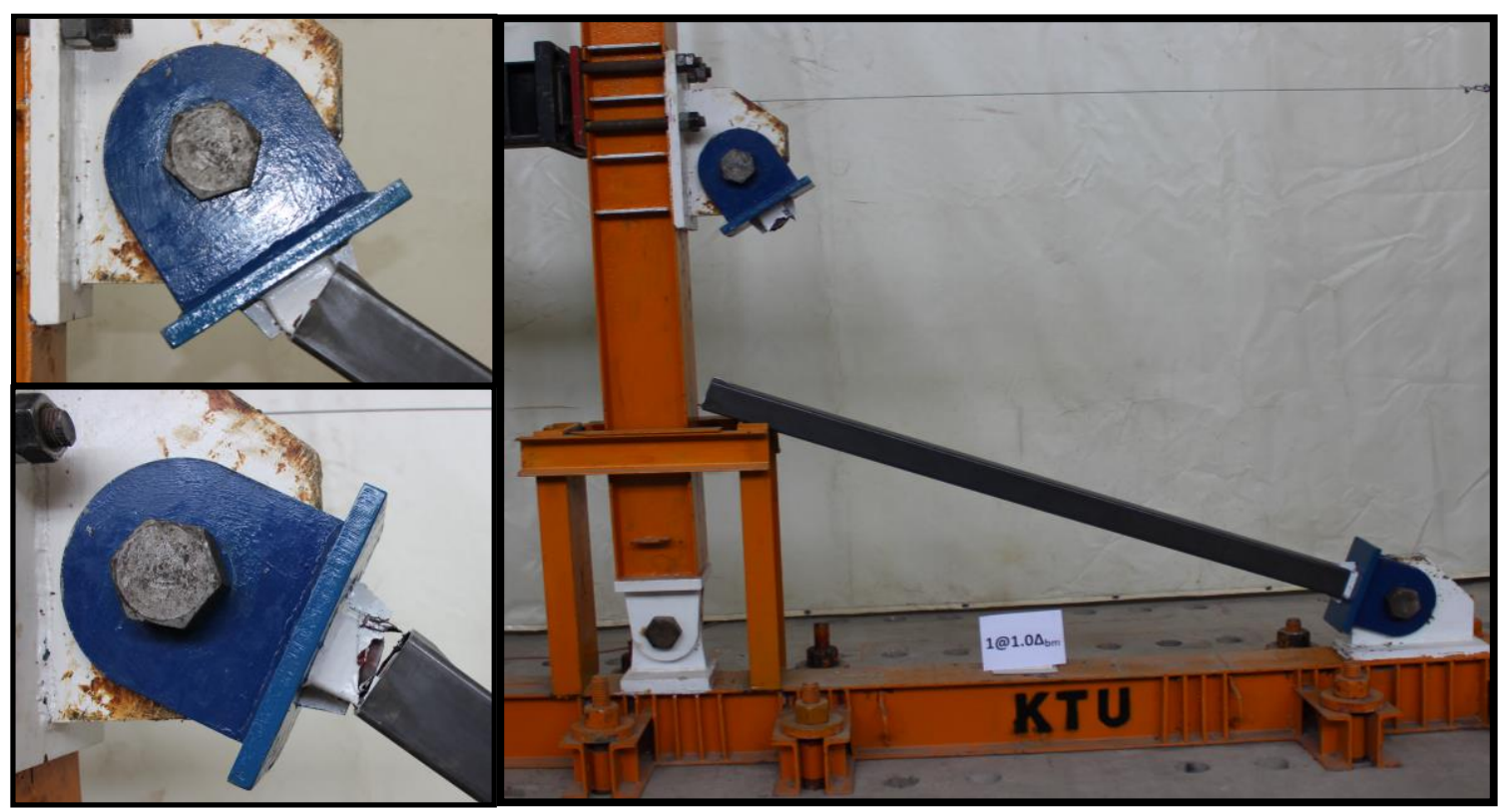

Şekil 8. ST elemanının göçme anı

Deney elemanlarının çevrimsel yük-yerdeğiştirme eğrilerine göre elde edilen zarf eğrileri Şekil 9' da verilmektedir. $\mathrm{Bu}$ eğriden görüldüğ̈̈ üzere, deney elemanları çekme yükü etkisinde benzer bir davranış sergilemiş, itme yükü etkisinde ise ST elemanı GÇ elemanına göre daha iyi bir performans göstermiştir. İtmede her iki deney elemanı da akma yüküne yaklaşık olarak aynı yatay yerdeğiştirme değerinde ulaşmış, ancak ST elemanının akma yükü GÇ elemanına göre \%12,6 daha fazla olarak elde edilmiştir. Bununla birlikte GÇ elemanı akma yüküne ulaşır ulaşmaz burkulmaktadır. ST elemanında ise iç ve dış burkulma önleyiciler nedeniyle $9.22 \mathrm{~mm}$ 'lik bir yerdeğiştirme değerine kadar burkulma kontrolü sağlanmıştır. ST elemanının burkulma yükü ve yerdeğiştirmesi, GÇ elemanına göre sırasıyla $\% 30.8$ ve \%80 daha fazla olarak elde edilmiştir. Burkulma kontrolü sayesinde ST elemanı itme yüklemesinde çekme yüklemesine yakın bir yük taşıma kapasitesi göstermiş olup itme ve çekmede yaklaşık olarak aynı başlangıç rijitliğine sahiptir. 


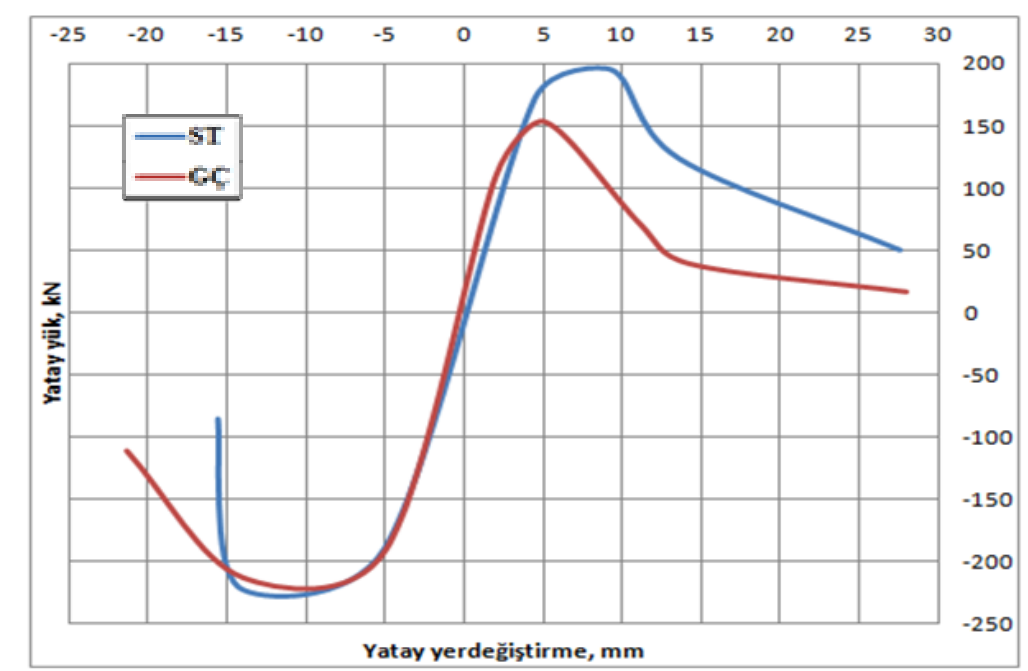

Şekil 9. Deney elemanlarının zarf ĕgrileri

Deney elemanlarının çevrimsel yük-yerdeğiştirme eğrilerinin altında kalan alanlara göre hesaplanan kümülatif enerji tüketme kapasiteleri Şekil 10' da verilmektedir. ST ve GÇ elemanlarının deney sonunda tükettikleri toplam enerji sırasıyla $13.78 \mathrm{~kJ}$ ve $11.60 \mathrm{~kJ}$ olarak elde edilmiştir. Buradan ST elemanın GÇ elemanına göre \%19 civarında daha fazla bir enerji tüketme kapasitesi olduğu görülmektedir.

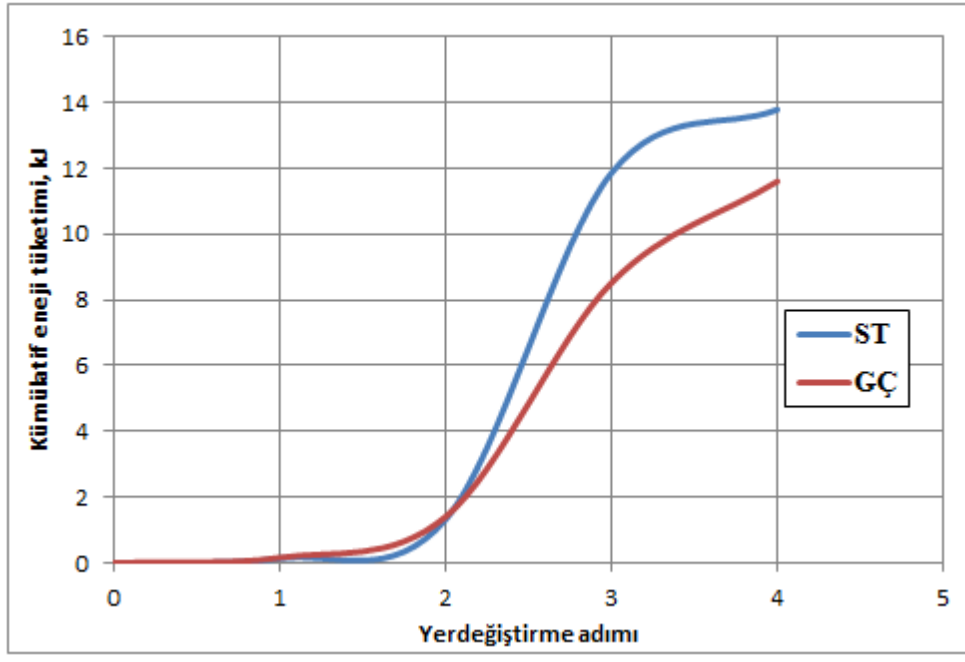

Şekil 10. Deney elemanlarının enerji tüketme kapasiteleri

\section{SONUCLAR}

Bu çalışmada, kutu enkesitli çelik çaprazlarda burkulma kontrolü sağlamak için önerilen sandviç tipi çelik çaprazların davranışları deneysel olarak incelenmiş ve elde edilen bulgular kutu enkesitli geleneksel bir çelik çapraz ile karşılaştırılmıştır. Sonuç olarak, sandviç tipi çelik çaprazlarda kullanılan iç ve dış burkulma önleyiciler sayesinde etkili bir burkulma kontrolünün sağlandığı; bununla birlikte sandviç tipi çelik çaprazın çekmede olduğu gibi itmede de akma yüküne burkulma olmadan ulaştığı görülmüştür. Bu durum, sandviç tipi çelik çapraz için, itme ve çekmede yaklaşık olarak aynı başlangıç rijitliğinin elde edilmesini sağlamıştır. Nihai durumda sandviç tipi çelik çaprazda meydana gelen burkulma, tasarım gereği burkulma kontrolünün sağlanamadığı kenar boşluklarından birinde meydana 
gelmiştir. $\mathrm{Bu}$ durumun önlenmesi için, sandviç tipi çelik çaprazların kenar boşluğu bırakılan bölgelerde içten çelik levhalarla rijitleştirilerek kullanılması önerilmektedir.

\section{KAYNAKLAR}

[1] B. M. Broderick, A. Y. Elghazouli and J. Goggins, "Earthquake testing and response analysis of concentrically-braced sub-frames," Journal of Constructional Steel Research, vol. 64, pp. 997-1007, 2008.

[2] R. Tremblay, "Seismic behavior and design of concentrically braced steel frames," AISC Engineering Journal, vol. 38, no. 3, pp. 148-166, 2001.

[3] A. Aguero, C. Izvernari and R. Tremblay, "Modelling of the seismic response of concentrically braced steel frames using the OpenSees analysis environment," International Journal of Advanced Steel Construction, vol. 2, no. 3, pp. 242-274, 2006.

[4] Ç. Avcı Karataş, O. C. Çelik, "Çelik Çekirdekli Burkulması Önlenmiş Çaprazların (BÖÇ) Tasarımı, Üretimi ve Deneysel İncelenmesi," Teknik Dergi, c. 30, s. 1, 2019.

[5] S. A. R. Tabatabaei, S. R. Mirghaderi and A. Hosseini, "Experimental and numerical developing of reduced length buckling-restrained braces," Engineering Structures, vol. 77, pp. 143$160,2014$.

[6] M. E. Eryasar and C. Topkaya, "An experimental study on steel-encased buckling-restrained brace hysteretic dampers," Earthquake Engineering and Structural Dynamics, vol .39, pp. 561-581, 2010.

[7] N. Hoveidae and B. Rafezy, "Overall buckling behavior of all-steel buckling restrained braces," Journal of Constructional Steel Research, vol. 79, pp. 151-158, 2012.

[8] J. Shen, O. Seker, N. Sutchiewcharn and B. Akbas, "Cyclic behavior of buckling-controlled braces," Journal of Constructional Steel Research, vol. 121, pp. 110-125, 2016. 